\title{
Diretrizes pedagógicas e a construção do projeto pedagógico local: uma construção coletiva necessária
}

\author{
Pedagogical Guileines and the construction of the local pedagogical project: a \\ necessary collective construction
}

\author{
Ana Lúcia Fernandes ${ }^{l}$ \\ Ingrid Finkler Cavion ${ }^{2}$
}

\begin{abstract}
RESUMO
Este artigo aborda questões relacionadas à gestão e ao processo de elaboração do Projeto políticopedagógico (PPP). A análise foi feita tendo como referência o documento guia, de cunho teóricometodológico, elaborado pelo Órgão Regulador e o Projeto político-pedagógico (PPP) de uma escola da magistratura no Rio Grande do Sul. Aponta a emergência de conceitos estruturantes quanto às abordagens do processo de ensino, ao processo de aprendizagem, e a relação entre inovação e formação específica. Aspectos estes que estão relacionados entre si e a outros fatores que fazem parte da dinâmica educativa, mas, neste artigo, ganham especial ênfase. O artigo também busca compreender como a coordenação pedagógica lida com essas questões, com vistas à ressignificação e a inovação nas práticas educativas. A análise documental identificou pontos mais frágeis que podem impactar na produção das subjetividades de alunos e professores desta escola e que merecem ser revistos em um processo de fortalecimento institucional.
\end{abstract}

Palavras-chave: Projeto político-pedagógico; Escola de formação; Inovação.

\begin{abstract}
This article discusses issues related to the management and the process of elaboration of the politicalpedagogical project (PPP). The analysis was carried out based on the guide document, of a theoreticalmethodological nature, elaborated by the Regulatory Body and the political-pedagogical project (PPP) of a judiciary training school in Rio Grande do Sul. It points to the emergency of structuring concepts regarding the approaches of the teaching process, the learning process, and the relationship between innovation and specific training. These aspects are related to one another and to other factors, which are part of the educational dynamics, but, in this article, they gain special emphasis. This article also seeks to understand how pedagogical coordination deals with these issues, with a view to resignification and innovation in educational practices. The documental analysis identified more fragile points that may impact the subjectivities of students and teachers at this school, which demands to be reviewed within a process of institutional strengthening.
\end{abstract}

Keywords: political-pedagogical project; Training School; Innovation

\footnotetext{
${ }^{1}$ Mestranda em Gestão Educacional pela Universidade do Vale do Rio dos Sinos-UNISINOS, Especialista em Gestão Educação pela Fundação Getúlio Vargas- FGV e Graduada em Pedagoga/ Supervisora Escolar pela Faculdade Ritter dos Reis. E-mail: anasupervisora@ gmail.com

${ }^{2}$ Mestranda em Gestão educacional pela Universidade do Vale do Rio dos Sinos-UNISINOS, Especialista em Gestão de Pessoas e Liderança Coach pela Universidade La Salle - UNILASALLE e Graduada em Educação Física - Licenciatura pela Faculdade da Serra Gaúcha - FSG E-mail: ingridcavion@gmail.com
} 


\section{Introdução}

A promoção da melhoria da qualidade dos sistemas educacionais, com o intuito de buscar respostas para novos problemas educativos passa, segundo Esteve (2004), pela modificação das condições de trabalho dos agentes do sistema educacional e a formação de professores.

O Documento Orientador para as Escolas, elaborado pelo Órgão Regulador, assume a condição de um Guia oficial para as instituições. Assume seu papel de formação e aperfeiçoamento dos estudantes e de seus formadores e contempla os marcos de natureza legal, assim como prevê referências básicas de caráter institucional e pedagógico, que subsidiam a elaboração dos Projetos políticopedagógicos locais (PPP). Sinaliza a preocupação em relação à construção do documento local, a fim de que seja problematizada a organização curricular. Essa problematização tem como objetivo levantar aspectos específicos e singulares de cada unidade e contemplar as dimensões humana, reflexiva, científica e tecnológica para a transformação das diferentes realidades. Destaca a preocupação e o compromisso nacional assumido em sua missão, com relação à formação das pessoas que fazem parte da instituição, de forma contextualizada e específica, sem perder de vista as questões presentes no âmbito da sociedade contemporânea. Tem como preocupação especial a promoção de espaços dialógicos que agreguem os aspectos formativos para o desenvolvimento das competências profissionais que, ao mesmo tempo, são interpelados por desafios de diferentes ordens. Implica, pois, colocá-los em discussão para o fortalecimento da atuação dos profissionais, no contexto em que participam. Assim, neste documento estão presentes os aspectos de natureza prática e teórica, que conjugadas, explicitam as diretrizes pedagógicas nacionais em diálogo permanente com o protagonismo e autonomia das escolas locais.

O Órgão Regulador reconhece que a elaboração do PPP local não se dá instantaneamente, nem nasce pronto, trata-se de uma historicidade que precisa ser considerada em seu processo de constituição. Dessa forma, foram desenvolvidas ações pelo Órgão com vistas a subsidiar e apoiar as escolas locais na elaboração dos documentos. A Instituição promoveu um workshop de dois dias em que estiveram presentes representantes das escolas, para troca de informações, ideias e conhecimentos, bem como orientações para auxiliar as escolas no processo. Embora cada instituição tenha seu próprio processo de elaboração deste documento, foi solicitado que cada uma das escolas pudesse elaborar seu cronograma de trabalho, com prazo combinado de envio para o Órgão Regulador, para que este pudesse organizar o acompanhamento e apoio, conforme as demandas locais.

A seguir são elencados alguns elementos que compõem o roteiro:

1. apresentação: breve histórico da escola; contextualização, as origens, o papel da escola, a missão, visão e os objetivos institucionais; 
2. os princípios que regem a situação da escola: princípios legais, princípios institucionais, princípios pedagógicos;

3. organização da escola;

4. organização curricular: orientações metodológicas. Modalidades e oferta de cursos;

5. avaliação e formas de acompanhamento do trabalho institucional;

6. plano de ação; (BRASİLIA, 2018, p. 9-10)

Cada escola deveria então enviar seu PPP para uma devolutiva da análise do Órgão Regulador e acrescentar outros elementos que julgasse relevante ou importante para ser considerado.

No Guia teórico-metodológico (2018, p.12) para a elaboração do Projeto político-pedagógico da instituição analisada, consta a sua preocupação quanto aos "desafios advindos do cumprimento dos direitos conquistados pelos indivíduos, os novos pilares da ciência contemporânea, o avanço tec- nológico e os impactos advindos das Tecnologias de Informação e Comunicação (TIC)", estes como grandes desafios para as propostas curriculares desenvolvidas pela rede de escolas. Nesse documento, fica evidenciada também a preocupação quanto ao protagonismo dos magistrados e seus formadores, quanto à forma de conviver com as transformações sociais e os impactos gerados sobre o desenvolvimento das competências dos profissionais. Além disso, é dito ali que é preciso elaborar novas formas de aprender e de estabelecer relações com o contexto mais amplo, na área de educação, e com seus processos formativos, numa perspectiva participativa e democrática de construção.

O quadro 1, apresentado a seguir, traz algumas questões destacadas no roteiro, no Guia, no PPP da escola e na Devolutiva da Análise do Documento. 
Quadro 1 - Percurso de implantação do PPP

\begin{tabular}{|c|c|c|c|}
\hline $\begin{array}{c}\text { ROTEIRO PARA } \\
\text { ELABORAÇÃO } \\
\text { DO PPP }\end{array}$ & $\begin{array}{l}\text { GUIA TEÓRICO- } \\
\text { METODOLÓGICO- } \\
\text { ÓRGÃO } \\
\text { REGULADOR }\end{array}$ & $\begin{array}{c}\text { PROJETO POLÍTICO- } \\
\text { PEDAGÓGICO- } \\
\text { ESCOLA }\end{array}$ & $\begin{array}{l}\text { DEVOLUTIVA } \\
\text { DA ANÁLISE DO } \\
\text { DOCUMENTO }\end{array}$ \\
\hline $\begin{array}{l}\text { 1. Apresentação: } \\
\text { breve histórico da } \\
\text { escola; contextuali- } \\
\text { zação, papel da } \\
\text { escola, missão, } \\
\text { visão e objetivos }\end{array}$ & $\begin{array}{l}\text { "Espera-se que que as } \\
\text { escolas concebam os } \\
\text { magistrados e seus for- } \\
\text { madores como protago- } \\
\text { nistas do próprio proces- } \\
\text { so de aprender, estimu- } \\
\text { lando formas de conviver } \\
\text { com as transformações } \\
\text { sociais e os seus impac- } \\
\text { tos sobre o desenvolvi- } \\
\text { mento de suas competên- } \\
\text { cias profissionais" }\end{array}$ & $\begin{array}{l}\text { Revisão do conteúdo. } \\
\text { Inconclusivo, necessita } \\
\text { ser revisto. Expor de } \\
\text { maneira contextualizada e } \\
\text { orgânica. Falta de defini- } \\
\text { ção da perspectiva histó- } \\
\text { rico-crítica, necessita de } \\
\text { contextualização. Suges- } \\
\text { tões de referências. Mis- } \\
\text { são, visão e valores norte- } \\
\text { adores deve ser discutido } \\
\text { em nível satisfatório para } \\
\text { a composição do item. }\end{array}$ & $\begin{array}{lr}\text { Sugestão: } & \text { breve } \\
\text { identificação da } \\
\text { escola e como ela } \\
\text { se alinha ao con- } \\
\text { texto da educação } \\
\text { judicial. }\end{array}$ \\
\hline $\begin{array}{l}\text { 2. Princípios legais, } \\
\text { institucionais e } \\
\text { pedagógicos, que } \\
\text { regem a atuação da } \\
\text { escola }\end{array}$ & $\begin{array}{l}\text { Indica a natureza da } \\
\text { formação: humanista e } \\
\text { interdisciplinar; } \\
\text { Processo de produção do } \\
\text { conhecimento: reconhe- } \\
\text { cimento da indissociabi- } \\
\text { lidade entre o conheci- } \\
\text { mento como realidade no } \\
\text { pensamento que ganha } \\
\text { concretude na ação. } \\
\text { Princípios pedagógicos: } \\
\text { relação teoria e prática, } \\
\text { interdisciplinaridade, } \\
\text { reflexão crítica da prática } \\
\text { laboral, relação entre } \\
\text { conhecimento e media- } \\
\text { ções pedagógicas, apren- } \\
\text { dizagens construídas com } \\
\text { base na problematização } \\
\text { entre parte e totalidade. }\end{array}$ & $\begin{array}{l}\text { Os princípios são apenas } \\
\text { citados é necessário a } \\
\text { contextualização dos } \\
\text { referidos princípios para a } \\
\text { instituição. Necessário } \\
\text { explicitar os princípios } \\
\text { legais, institucional e } \\
\text { pedagógicos, consideran- } \\
\text { do as Diretrizes do Órgão } \\
\text { Regulador. }\end{array}$ & $\begin{array}{lr}\text { Reflexão da escola } \\
\text { quanto a unicidade } \\
\text { da sua organização } \\
\text { pedagógica } \\
\text { demonstrar trans- } \\
\text { versalmente } \\
\text { princípios e } \\
\text { cepções. }\end{array}$ \\
\hline
\end{tabular}




\begin{tabular}{|c|c|c|c|}
\hline $\begin{array}{l}\text { 3. Organização da } \\
\text { escola, funções da } \\
\text { escola }\end{array}$ & $\begin{array}{l}\text { Dotados de uma intenci- } \\
\text { onalidade, ocorrem por } \\
\text { mediações sistematizadas } \\
\text { que, desenvolvidas em } \\
\text { contextos culturais defi- } \\
\text { nidos, promovem o inter- } \\
\text { câmbio de experiências } \\
\text { individuais e coletivas. } \\
\text { Nessa direção, visam } \\
\text { possibilitar o acesso a } \\
\text { conhecimentos, técnicas } \\
\text { ou dimensões culturais } \\
\text { produzidas pela socieda- } \\
\text { de em seu processo de } \\
\text { desenvolvimento históri- } \\
\text { co. }\end{array}$ & $\begin{array}{l}\text { Necessário contextualiza- } \\
\text { ção e reflexão acerca: da } \\
\text { organização da escola nos } \\
\text { âmbitos administrativos, } \\
\text { pedagógicos, financeiro e } \\
\text { jurídico; das instâncias de } \\
\text { decisão, da estrutura físi- } \\
\text { ca; estrutura pedagógico- } \\
\text { administrativa; do públi- } \\
\text { co-alvo; do corpo docen- } \\
\text { te; dos aspectos relacio- } \\
\text { nados ao controle de } \\
\text { frequência, certificação, } \\
\text { divulgação dos cursos, } \\
\text { parcerias. Tomada de } \\
\text { posição da escola em } \\
\text { relação às Diretrizes regi- } \\
\text { onais e nacionais. }\end{array}$ & $\begin{array}{l}\text { Estabelecer a dire- } \\
\text { ção e formas de } \\
\text { organização da } \\
\text { escola e de como se } \\
\text { articulam os diver- } \\
\text { sos setores que } \\
\text { contribuam para o } \\
\text { processo educativo, } \\
\text { revelando as suas } \\
\text { funções. }\end{array}$ \\
\hline $\begin{array}{l}\text { 4. Organização } \\
\text { curricular: orienta- } \\
\text { ções metodológicas, } \\
\text { modalidades e ofer- } \\
\text { ta de cursos }\end{array}$ & & $\begin{array}{l}\text { Descrição da organização } \\
\text { metodológicas e modali- } \\
\text { dades de forma superficial } \\
\text { e incipiente. Indicação de } \\
\text { referências para subsidiar } \\
\text { o trabalho. Concepção de } \\
\text { currículo, de formação } \\
\text { inicial e continuada, cur- } \\
\text { sos que oferta, conexão } \\
\text { entre os temas com o } \\
\text { contexto social mais am- } \\
\text { plo e regional. Perfil do } \\
\text { formador e de egresso. } \\
\text { Relação ensino, pesquisa } \\
\text { e extensão. }\end{array}$ & $\begin{array}{l}\text { Identificar a inter- } \\
\text { relação curricular } \\
\text { com o contexto } \\
\text { social e suas cone- } \\
\text { xões com a cons- } \\
\text { trução e desenvol- } \\
\text { vimento do conhe- } \\
\text { cimento. Indicar as } \\
\text { modalidade e o } \\
\text { desenho curricular } \\
\text { com as quais a } \\
\text { escola atua e como } \\
\text { se dá a oferta dos } \\
\text { cursos. }\end{array}$ \\
\hline $\begin{array}{l}\text { 5. Avaliação e for- } \\
\text { mas de acompa- } \\
\text { nhamento do traba- } \\
\text { lho institucional }\end{array}$ & $\begin{array}{l}\text { Pressupõe a integração } \\
\text { de todo o processo peda- } \\
\text { gógico, visando garantir } \\
\text { validade às soluções } \\
\text { educacionais e aos resul- } \\
\text { tados obtidos nesse } \\
\text { mesmo processo, tendo a } \\
\text { ética como elemento } \\
\text { norteador da avaliação } \\
\text { formativa. }\end{array}$ & $\begin{array}{l}\text { Ampliar a reflexão sobre } \\
\text { a avaliação da aprendiza- } \\
\text { gem-concepção e formas } \\
\text { de operacionalização; } \\
\text { Ampliar reflexão sobre a } \\
\text { Avaliação institucional - } \\
\text { concepção e formas de } \\
\text { operacionalização; } \\
\text { Explicitação dos instru- } \\
\text { mentos que podem ser } \\
\text { utilizados para coletar os } \\
\text { instrumentos de desem- } \\
\text { penho. }\end{array}$ & $\begin{array}{l}\text { Concepção de } \\
\text { avaliação e proce- } \\
\text { dimentos de avalia- } \\
\text { ção. Divisão entre } \\
\text { as modalidades de } \\
\text { curso e avaliação } \\
\text { institucional e auto- } \\
\text { avaliação. }\end{array}$ \\
\hline
\end{tabular}




\begin{tabular}{|c|c|c|c|}
\hline 6. Plano de ação & $\begin{array}{l}\text { [...] ganha relevância e } \\
\text { validade a definição de } \\
\text { um bom e adequado } \\
\text { conjunto de indicadores } \\
\text { para avaliar, de forma } \\
\text { simples, segura e acessí- } \\
\text { vel, a qualidade da for- } \\
\text { mação ofertada por meio, } \\
\text { dos cursos [...] estes } \\
\text { indicadores podem per- } \\
\text { mitir então, a construção } \\
\text { de um quadro de sinais } \\
\text { que possibilitem identifi- } \\
\text { car o que vem dando } \\
\text { certo e o que precisa } \\
\text { melhorar }\{. . .] \text { o que deve } \\
\text { ter parâmetros estabele- } \\
\text { cidos no PPP. }\end{array}$ & $\begin{array}{l}\text { Não está contemplado no } \\
\text { PPP. Incluir objetivos, } \\
\text { metas, ações, cronograma } \\
\text { e avaliação; } \\
\text { Atentar para a coesão e } \\
\text { coerência entre eles; } \\
\text { Qualificar as metas esta- } \\
\text { belecidas como compro- } \\
\text { misso expresso em termos } \\
\text { de objeto a ser alcançado. }\end{array}$ & $\begin{array}{l}\text { Cronograma de } \\
\text { trabalho do próprio } \\
\text { projeto, formas de } \\
\text { aprovação, implan- } \\
\text { tação e implemen- } \\
\text { tação do PPP. Indi- } \\
\text { ca o cronograma } \\
\text { das atividades de } \\
\text { rotina escolar e } \\
\text { cronograma das } \\
\text { atividades à longo } \\
\text { prazo. }\end{array}$ \\
\hline 7. Referências & $\begin{array}{l}\text { As referências citadas } \\
\text { oferecem subsídios para } \\
\text { a reflexão e construção } \\
\text { de conceitos pela comu- } \\
\text { nidade escolar local, de } \\
\text { forma autônoma e criati- } \\
\text { va. Levando em conta } \\
\text { sua realidade local. A } \\
\text { opção de trabalho poderá } \\
\text { contribuir para aproximá- } \\
\text { la da dinâmica da ação- } \\
\text { reflexão-ação, em relação } \\
\text { aos processos formativos } \\
\text { que realiza, bem como } \\
\text { distanciá-la da perspecti- } \\
\text { va de mera elaboração de } \\
\text { documentos. }\end{array}$ & $\begin{array}{l}\text { Precisa de referências } \\
\text { para suporte conceitual do } \\
\text { texto e suporte para as } \\
\text { discussões. }\end{array}$ & $\begin{array}{l}\text { Listagem das refe- } \\
\text { rências consultadas } \\
\text { e citadas no texto. }\end{array}$ \\
\hline
\end{tabular}

Fonte autoral

A orientação do Órgão Regulador era de que cada escola refletisse acerca das diretrizes, de forma participativa e democrática, e desencadeasse o processo de elaboração do seu PPP, acrescentando ou subtraindo elementos que julgasse relevantes ou significativos para a sua comunidade local.

São relacionados, a seguir, alguns conceitos estruturantes quanto às abordagens vinculadas ao processo de ensino e de aprendizagem e a forma como a coordenação pedagógica lida com estas questões, com vistas à res- significação e a inovação nas práticas educativas.

\section{Processos de ensino}

Parte-se do entendimento de que a forma como as instituições se organizam denota o trabalho que está sendo produzido em seu interior. Esta é uma afirmação que, de certa forma, provoca inquietação quanto à compreensão e à conceitualização das relações entre a organização do ensino e as forças que podem orientar e contrariar 
sua evolução, conforme Thurler e Maulini (2012). Nessa perspectiva, ainda segundo Thurler e Maulini (2012), o trabalho é entendido como uma construção social e, como tal, pode transformar as condições de produção do trabalho ou gerar outra maneira de produzir a atividade humana de produção. Portanto, o entendimento de como se dá o trabalho pedagógico na instituição analisada, remete ao entendimento de como acontece o processo de ensino, o processo de aprendizagem e a relação entre inovação e formação específica, gerando impacto nas questões sociais.

A instituição analisada descreve em seu Guia que "uma educação orientada para a recepção e mera reprodução do conhecimento" não responde às demandas sociais. E, em contrapartida, que "outras perspectivas teóricas e práticas de enfrentar os desafios postos à educação, no contexto social atual", promovem meios que substituem "a passividade dos sujeitos pela sua participação ativa e crítica [...] sem perder os laços de solidariedade social”. (BRASİLIA, 2018, p.13). A devolutiva direciona para a relevância da identificação, pela comunidade educativa, da sua concepção de currículo, de formação inicial e continuada e dos cursos que oferta. Aponta, também, a importância de eleger temas dos cursos que estabelecem conexão com o contexto social local, assim como as abordagens metodológicas adotadas pela equipe pedagógica, e as competências necessárias para o ensino e aprendizagem, além de como o ensino, a pesquisa e a extensão são articulados.
Ao analisar essa orientação, percebe-se a importância do sentido e significado de uma situação-problema, como promotora de aprendizagem. O "lugar" do erro, do contexto e das perguntas, como aspectos estruturantes do ensino, voltado para o desenvolvimento de competências que serão pontuados a seguir.

Perrenoud (2002), ao questionar a didática, declara a importância de o professor organizar e dirigir situações de aprendizagem, ou seja, considerar as características, ritmos, motivações dos alunos, dando novo significado à escola e às situações que podem promover a aprendizagem. Requer novas competências para ensinar em um contexto de situações-problema. Mas esta proposição necessita de um tempo em que só pode ser "sendo", nem antes, nem depois, mas na própria situação de aprendizagem em que o aluno está envolvido. Assim, uma situação - problema tem como característica "vivê-la sendo atravessados pelos desafios, obstáculos, perturbações, riscos, e tomadas de decisão". (PERRENOUD, 2002, p.119). O erro, nessa perspectiva, assume como significado a construção de novas aprendizagens e outras possibilidades de aperfeiçoamento.

Nesse sentido, o Órgão Regulador orienta que sejam identificados os procedimentos para avaliação, além de verificar se os princípios que a regem estão alinhados à concepção pedagógica. Inclusive, observam a avaliação institucional e a autoavaliação como portadores de evidências do que é feito, porque é feito e qual a importância dessas ações no processo de 
aprendizagem e no processo de ensino da escola, no seu contexto específico (BRASÍLIA, 2018).

Requer também que o professor elabore questões desafiadoras que envolvam análise, compreensão, tomada de decisão e que sejam bem formuladas e instigantes, a fim de que possa avaliar o processo de aprendizagem de seus alunos. Nesse sentido, os indicadores são sinais, marcas, informações e o conjunto de ideias, representações, lembranças entre outros, que se configuram como um conjunto de elementos indispensáveis para a tomada de decisão. Para além da mera reprodução de conteúdo ou até da verificação dos mesmos, é fundamental também que o professor proponha três tipos de questões de interação: primeiro, construir ou considerar as diferentes partes que correspondem aos elementos constituintes da situaçãoproblema como um todo. Segundo, articular ou coordenar cada uma das partes ou elementos disponíveis com o próprio todo. Terceiro, tomar o todo como o que estruturam, dá sentido e, por isso, regula toda a situação (PERRENOUD, 2002, p. 121-122).

\section{Mas, hoje o que significa ser competente?}

De acordo com Macedo (2002), ser competente significa preservar o passado como organizador de nosso presente no que ele tem de melhor. Organizar o presente tendo como referência o futuro, considerando toda a incerteza, a loucura e sua insensatez, mas, ao mesmo tempo, considerando toda a esperança, toda a abertura, toda a novidade, todas as facilidades que ele pretende proporcionar-nos. Assim, as situações propõem desafios em que os sujeitos devem mobilizar recursos, ativar esquemas e tomar decisões para dar conta dos desafios postos a cada um, e a todos.

Porém, a competência "sempre tem uma dimensão relacional porque expressa, no plano interno ao sujeito, o desafio de diferenciar e integrar as partes e o todo que estruturam e organizam suas interações com o mundo e consigo mesmo, ao mesmo tempo em que expressa a dimensão interdependente entre sujeito e objeto" (MACEDO, 2002, p. 126). Assim, envolve a forma como as pessoas se relacionam e interagem nas relações interpessoais, como também nas relações institucionais.

$\mathrm{Na}$ devolutiva encaminhada à escola, fica evidenciada a preocupação quanto aos princípios que regem a atuação da escola e aos princípios institucionais, legais e pedagógicos. Questões estas que anunciam e pretendem consolidar a identidade institucional da escola.

\section{Processo de aprendizagem}

Entende-se como papel da educação o desenvolvimento de competências em situações contextualizadas. Uma boa situação-problema "mobiliza os recursos a que o aluno pode recorrer naquele momento ou circunstância" na medida em que "mobiliza recursos afetivos, cognitivos" e envolve igualmente " saber agir, saber dizer, saber comunicar, saber fazer, saber explicar, saber compreender [...]" (MACEDO, 
2002, p.125). Thurler e Maulini (2002) dizem que, para promover transformações, é preciso ação, trabalho, emprego racional dos meios para gerar resultados esperados.

De acordo com as Diretrizes Pedagógicas da instituição analisada, a abordagem metodológica e a problematização dos conteúdos curriculares estão relacionadas ao:

(i) desenvolvimento de competências dos magistrados com base tanto em sua atuação profissional como na realidade social que o circunda; (ii) favorecimento da tomada de decisão diante de situações concretas; (iii) estímulo à aprendizagem autônoma dos indivíduos, fundamentada na pesquisa. (BRASÍLIA, 2018, p.15)

Da mesma forma, a análise e a crítica, numa situação de caráter concreto, permitem, segundo Perrenoud (2002), que o aluno formule efetivamente hipóteses e conjecturas, assumindo seu protagonismo diante do seu próprio processo de aprendizagem. Significa dizer que o aluno desenvolve sua capacidade de questionamento frequentemente em relação as questões que estão à sua volta. Como desafio intelectual, como algo a ser superado, tal ato envolve planejamento, riscos, reflexão, tematização, disputa, enfrentamento de conflitos, tensões, paradoxos, alternativas diversificadas ou argumentações.

Thurler e Maulini (2012, p.24) afirmam que a inovação "teve de lutar para abrir caminho, mas certamente encontra eco hoje, quando os professores têm a preocupação de tornar seus alunos "ativos" e reorientam as ativi- dades conforme elas tenham "andado", "evoluído" ou "funcionado mais ou menos bem".

Conforme o Guia, as intensas e velozes transformações sofridas em diferentes contextos sociais implicam mudanças necessárias e importantes no âmbito educacional e na relação que se estabelece com o conhecimento. Anuncia, também, aspectos relacionados às transformações e a vários significados para a vida em sociedade, assim como aos direitos conquistados pelos indivíduos, aos novos pilares da ciência contemporânea, ao avanço tecnológico e seus impactos na maneira com que passamos a nos relacionar com o conhecimento e com o outro (BRASÍLIA, 2018).

Nessa perspectiva, os núcleos de estudos da escola proporcionam espaços para discussões qualificadas, boas práticas, bem como a promoção da excelência da prestação jurisdicional e a busca da inovação e soluções criativas, que melhorem o processo jurisdicional e, ao mesmo tempo, tenham significativo impacto social. Considera, como desafio, que cada escola conceba "os magistrados e seus formadores como protagonistas do próprio processo de aprender, estimulando formas de conviver com as transformações sociais e os seus impactos sobre o desenvolvimento de suas competências profissionais". (BRASÍLIA, 2018, p. 12).

$\mathrm{O}$ fato de que "os saberes que os professores desenvolveram geralmente são gerados com muito pouco cuidado", pois "não existe o hábito de descrever e analisar os processos em curso; nunca se avaliam as experiên- 
cias coletivas vividas no quadro de projetos pedagógicos, muito menos elas são capitalizadas mediante escritos", embora as escolas tenham aprendido muito, "se ocultem nelas tesouros de saber, elas não os conhecem e apenas raramente se munem dos meios para descobri-los" (THURLER; MAULINI, 2012, p.82).

\section{Inovação e formação}

Macedo (2002, p.125) anuncia um cenário em que "além do passado como organizador do presente, também temos o futuro, a tecnologia, com suas surpresas, suas novas oportunidades, seus valores alternativos". Isso contribui para uma mudança de paradigma e anuncia novos modos de aprender e de estabelecer relações entre o processo de formação e a sociedade do conhecimento. O autor reconhece a importância do passado, principalmente no que se refere aos valores, ao mesmo tempo em que reconhece que temos como novidade é que "também temos o futuro como organizador do presente".

Nesse sentido, o Órgão Regulador reconhece que "a educação tem sido desafiada pelas mudanças ocorridas nas práticas sociais, no mundo do trabalho e nos processos de globalização da economia e das culturas" (BRASÍlIA, 2018, p.13), assumindo o compromisso institucional do desenvolvimento de uma educação voltada para a "formação humana" e que privilegie "a promoção de capacidades críticas, analíticas e propositivas em relação à realidade social e à própria cons- trução do conhecimento". (BRASÍLIA, 2018, p. 13).

Gadotti (2000, p.37) corrobora com a perspectiva de que "todo projeto supõe rupturas com o presente e promessas para o futuro" o que "significa tentar quebrar um estado confortável para arriscar-se, atravessar um período de instabilidade e buscar uma nova estabilidade em função da promessa que cada projeto contém de estado melhor do que o presente". Para ele, "um projeto educativo pode ser tomado como promessa frente a determinadas rupturas" e "as promessas tornam visíveis os campos de ação possível, comprometendo seus atores e autores" ao mesmo tempo em que "o projeto político-pedagógico da escola é, por isso mesmo, sempre um processo inconcluso, uma etapa em direção a uma finalidade que permanece como horizonte da escola".

\section{Coordenação pedagógica e sua "presença"}

Segundo Thurler e Maulini (2002), os sistemas escolares estão engajados na mudança de modelos tradicionais de gestão, autoritários e centralizadores, para ou modelos mais participativos.

Um estabelecimento escolar se estrutura tendo um conjunto organizado de profissionais que necessitam assumir coletivamente uma tripla responsabilidade:

\footnotetext{
a) desenvolver os melhores dispositivos de ensino-aprendizagem para ajudar os alunos a atingir os objetivos fixados para o final de seu ciclo de estudos;
} 
b) identificar continuamente as mudanças estruturais e pedagógicas necessárias para integrar as novas metodologias;

c) instaurar um clima e um método de trabalho e de formação que permitam explorar o desenvolver de maneira ótima as competências individuais e coletivas existentes. (THURLER; MAULINI, 2002, p.62)

Os autores alertam que, para isso, é essencial que os profissionais sejam ou se tornem os principais atores e responsáveis pelas mudanças a serem feitas em seu estabelecimento escolar. Dessa forma, os profissionais devem ser ou tornarem-se os principais atores e responsáveis pelas mudanças a serem feitas em seu estabelecimento escolar.

Implica, segundo os mesmos autores, que os membros das equipes pedagógicas assumam maior responsabilidade coletiva, não apenas no que diz respeito à exploração e ao uso de novos dispositivos didáticos, mas numa verificação permanente das repercussões das escolas e, com nessa verificação, permitam introduzir os ajustes necessários. Significa, então, transformar as escolas em comunidades profissionais, centradas na aprendizagem interativa, que têm como alvo, melhorar as aprendizagens dos alunos.

De acordo com Paro (2010), o recurso subjetivo de cada trabalhador, de acordo com sua capacidade de trabalho, consiste em seu esforço na realização de ações que concorram para a concretização do objetivo. Ao mesmo tempo em que, na administração de uma empresa, não se trata do esforço de um indivíduo isolado, "mas de esforço humano coletivo, ou seja, da multiplicidade de habilidades, forças, destrezas, conhecimento, enfim as mais diferentes capacidades presentes nos diferentes componentes humanos da organização" (PARO, 2010, p.767).

Paro (2010, p.768), ao se referir à especificidade do trabalho na educação, esclarece que "a coordenação não precisa ser feita sempre a partir de um coordenador unipessoal que determine a conduta de grupos e pessoas", mas que potencialize a especificidade do trabalho pedagógico.

Nesse sentido, a relevância do papel do coordenador pedagógico, em seu papel de gestão, está nucleada na conjugação dos elementos do currículo: pessoas e processos. Caracteriza-se pelo que congrega, reúne, articula, enfim, somar e não dividir o conhecimento, a formação e a prática, como partes de um todo, de um projeto comum, segundo Rangel (2003). E, como objeto de seu trabalho, "o desenvolvimento qualitativo da organização escolar e dos que nela realizam seu trabalho de estudar, ensinar ou apoiar a função educativa por meio de aprendizagens individuais e coletivas" (ALARCÃO, 2004, p.35).

Assim sendo, para se alcançar a qualidade almejada, deve-se considerar, primordialmente, o "quanto os alunos estão avançando, evoluindo no aprendizado", quais "intervenções são necessárias e como ganham sentido quando pensadas no e com o coletivo", que é quando "o trabalho colaborativo ganha sentido" (SOUZA e COSTA, 
2017, p.119). Acredita-se que o estabelecimento escolar só pode tornar-se

um lugar onde a mudança é construída, coletiva e progressivamente, se os atores que dele fazem parte dispuserem de margens de manobra suficientes para conceber seu projeto e para inventar dispositivos suscetíveis de resolver os problemas encontrados. (THURLER; MAULINI, 2002, p.94)

Entende-se, dessa forma, que o coordenador pedagógico pode criar espaços para que estas margens de manobra ocorram.

Neste texto, foi possível relacionar alguns pontos de fragilidades que podem impactar na produção das subjetividades de alunos e professores desta escola, e que merecem a atenção e os encaminhamentos apropriados, com vistas à sua superação, baseado no trabalho pedagógico coletivo.

\section{Considerações finais}

Ao analisar as definições e diretrizes descritas pelo Órgão Regulador e as rotinas que afetam a elaboração do Projeto político-pedagógico local, foram ressaltados aspectos que se constituem como eixos estruturantes no texto: processo de ensino, processo de aprendizagem, inovação e formação, coordenação pedagógica e sua "presença". Em se tratando de um Documento Orientador para as Escolas, elaborado pelo Órgão Regulador que assume seu papel de formação e aperfeiçoamento dos estudantes e de seus formadores, representa pontos de identidade institucional e marcos de natu- reza legal, bem como as referências básicas de caráter institucional e pedagógico, que subsidiam a elaboração dos Projetos político-pedagógicos locais (PPP).

Dada a relevância deste trabalho, é possível perceber que há pontos frágeis que podem impactar de forma importante no processo de produção das subjetividades de alunos e professores desta escola. Questões estas relacionadas principalmente quanto à modificação das condições de trabalho dos formadores e na formação dos alunos como protagonistas.

Além disso, localmente, a escola é responsável por estabelecer novas formas de aprender, e de refletir sobre seus processos formativos da equipe e dos alunos, ao mesmo tempo em que fica evidente a necessidade de que a escola problematize a organização curricular, a fim de estabelecer novas formas de aprender e ensinar, tendo como base a reflexão e o diálogo. Significa que a construção de um caminho requer que este seja contextualizado e específico, sem perder de vista os desafios contemporâneos, para o fortalecimento da atuação e participação dos profissionais.

Outro aspecto evidenciado é quanto à forma como a coordenação pedagógica lida com essas questões na medida em que se ocupa da gestão pedagógica da instituição. A presença da coordenação pedagógica está na criação de estratégias de formação e de ação pedagógica com vistas a produção de resultados como produto da ação coletiva. Nesse sentido, a presença da coordenação está na criação de espaços e de tempos de formação do- 
cente, tendo o diálogo como eixo estruturante, para a ressignificação e a inovação nas práticas educativas.

O PPP precisa ser contínuo e sistemático e os aspectos apontados tornam-se essenciais para o fortalecimento institucional e para a melhoria contínua do processo do processo de formação de alunos e professores. 


\section{Referências}

ALARCÃO, I. Do olhar supervisor ao olhar sobre supervisão. Supervisão pedagógica: princípios e práticas. 4. ed. Campinas, 2004.

ESTEVE, J.M. A Terceira revolução Educacional. São Paulo: Moderna, 2004.

GADOTTI, M. O projeto político-pedagógico da escola na perspectiva de uma educação para a cidadania. Perspectivas atuais da educação. Porto Alegre: Artes Médicas Sul, 2000.

MACEDO, L. Situação-problema: forma e recurso de avaliação, desenvolvimento de competências e aprendizagem escolar. As competências para ensinar no século XXI: a formação dos professores e o desafio da avaliação. Porto Alegre: Artmed Editora, 2002.

PARO, V. H. A educação, a política e a administração: reflexões sobre a prática do diretor de escola. Educação e Pesquisa. São Paulo, v. 36, n.3, p. 763-778, set./dez. 2010 .

PERRENOUD, P. As competências para ensinar no século XXI: a formação dos professores e o desafio da avaliação. Porto Alegre: Artmed Editora, 2002.

RANGEL, M. Supervisão do sonho à ação - uma prática em transformação. Supervisão Educacional para uma escola de qualidade. 4. ed. São Paulo: Cortez, 2003.

SOUZA, C.P.B.A. \& COSTA, D.M.V. O trabalho colaborativo do pedagogo entre os educadores: um estudo de caso. Práticas de coordenação pedagógica na escola pública. 1.ed. Curitiba: Appris, 2017.

THURLER, M. e MAULINI, O. A Organização do Trabalho Escolar: Uma Oportunidade para Repensar a Escola. Trad. Fátima Murad. Porto Alegre: Penso Editora LTDA, 2012.

SOUSA, J.V. Guia teórico-metodológico para a elaboração do projeto políticopedagógico. Escola Nacional de Formação e Aperfeiçoamento de Magistrados (2018). Disponível em: https://www.enfam.jus.br/projeto-politico-pedagogico. Acesso em: 08/05/2019.

$O(s)$ autor(es) se responsabiliza $(m)$ pelo conteúdo e opiniões expressos no presente artigo, além disso declara(m) que a pesquisa é original.

Recebido em 19/03/2020

Aprovado em 23/06/2020 